\title{
Quantitative Description of the Relation between Protein Net Charge and Protein Adsorption to Air-Water Interfaces
}

\author{
Peter A. Wierenga,,,$+ *$ Marcel B. J. Meinders, ${ }^{\dagger,}$ Maarten R. Egmond, \\ Alphons G. J. Voragen, $\$$ and Harmen H. J. de Jongh ${ }^{\dagger, \S}$ \\ Wageningen Centre for Food Sciences, P.O. Box 557, Diedenweg 20, 6700 AN, Wageningen, The Netherlands, \\ Wageningen University and Research Centre, Wageningen, The Netherlands, TNO Nutrition and Food \\ Research, Zeist, The Netherlands, and Utrecht University, Utrecht, The Netherlands
}

Received: February 25, 2005; In Final Form: May 27, 2005

\begin{abstract}
In this study a set of chemically engineered variants of ovalbumin was produced to study the effects of electrostatic charge on the adsorption kinetics and resulting surface pressure at the air-water interface. The modification itself was based on the coupling of succinic anhydride to lysine residues on the protein surface. After purification of the modified proteins, five homogeneous batches were obtained with increasing degrees of modification and $\zeta$-potentials ranging from -19 to $-26 \mathrm{mV}(-17 \mathrm{mV}$ for native ovalbumin). These batches showed no changes in secondary, tertiary, or quaternary structure compared to the native protein. However, the rate of adsorption as measured with ellipsometry was found to decrease with increasing net charge, even at the initial stages of adsorption. This indicates an energy barrier to adsorption. With the use of a model based on the random sequential adsorption model, the energy barrier for adsorption was calculated and found to increase from $4.7 k T$ to $6.1 k T$ when the protein net charge was increased from -12 to -26 . A second effect was that the increased electrostatic repulsion resulted in a larger apparent size of the adsorbed proteins, which went from 19 to $31 \mathrm{~nm}^{2}$ (native and highest modification, respectively), corresponding to similar interaction energies at saturation. The interaction energy was found to determine not only the saturation surface load but also the surface pressure as a function of the surface load. This work shows that, in order to describe the functionality of proteins at interfaces, they can be described as hard colloidal particles. Further, it is shown that the build-up of protein surface layers can be described by the coulombic interactions, exposed protein hydrophobicity, and size.
\end{abstract}

\section{Introduction}

The interfacial layer between two bulk phases has chemical, physical, and mechanical properties that are different from those of the bulk phases, and these properties can change as a result of the adsorption of molecules from the bulk solution. Proteins form a major group of biomacromolecules and are known to affect interfacial properties in many systems, resulting in much attention from a wide range of research fields (for reviews see refs 16, 34, and 36). A striking point in these reviews is the demand for a quantitative description of the relation between the molecular parameters of the protein and changes in the mesoscopic system parameters such as the adsorbed amount and surface pressure. 1,16,21,30,34,36 To satisfy this demand, a systematic approach to the problem is necessary. In previous work the role of exposed hydrophobicity was identified using chemical modification to selectively alter the exposed hydrophobicity of ovalbumin. ${ }^{44}$ Using the same approach in the present work, we aim to provide a quantitative description of the relation between electrostatic net charge of proteins and adsorption at the airwater interface. In this description we include the increase of adsorbed amount in time and the effect that the adsorbed proteins have on the surface pressure.

* Corresponding author. Phone: +31 317 485440. Fax: +31 317 484893. E-mail: peter.wierenga@wur.nl.

$\dagger$ Wageningen Centre for Food Sciences.

$\doteqdot$ Wageningen University and Research Centre.

$\S$ TNO Nutrition and Food Research.

"Utrecht University.
Effects of electrostatic interactions on adsorption behavior have been studied at both liquid and solid interfaces (for studies on adsorption at solid interfaces see refs 6, 19, 29, and 34). In the present work the focus is on the liquid-gas interface, which has the advantage that it contains no ionisable groups and that it is homogeneous, compared to solid interfaces. The first qualitative observations on the effects of net charge were based on the measurement of surface pressure in time for protein solutions at different $\mathrm{pH}$ values. Later, researchers used radioactive labeling or ellipsometry; both techniques have the benefit of measuring the adsorbed amount of protein directly. In these studies it was observed that the rate of adsorption and the total amount of adsorbed protein is highest at $\mathrm{pH}$ values close to the isoelectric point (iep or $\mathrm{p} I$ ) where the protein carries no net charge. ${ }^{7,17,18,31}$

However, changing the $\mathrm{pH}$ not only changes the charge but can also lead to changes in the globularity of the protein. Many proteins adopt a molten globule form at acidic $\mathrm{pH}(\mathrm{pH}<4.5),{ }^{22}$ a state where the protein has lost its tertiary conformation while retaining secondary structure. This limits the range at which the $\mathrm{pH}$ can be chosen to specifically study charge effects. Further, only few charged groups titrate in the $\mathrm{pH}$ range in which proteins are used in applications $(\mathrm{pH} \mathrm{5-8).} \mathrm{An} \mathrm{alternative}$ approach is then to screen the electrostatic charges by increasing the ionic strength. ${ }^{7,9,28,41}$ In this case the net charge on the protein is constant, while the interaction energy is decreased, effectively reducing the contribution of electrostatics to the observed 
phenomena. Decreasing electrostatic interactions were found to result in an increase in the kinetics of adsorption, the end value of the adsorbed amount, and the end value of surface pressure. However, no quantitative description of the observations is offered in these articles.

Only a few authors have tried to combine experimental results and theory to propose general equations describing the adsorption process. In the field of protein adsorption many models are based on the Ward and Tordai adsorption equation, ${ }^{44}$ which describes diffusion-controlled adsorption. A modification of this equation was proposed by Macritchie and Alexander ${ }^{32}$ to account for charge effects. This modification describes the buildup of a wall potential at the interface as a result of the adsorption of charged molecules. More recently, it has been postulated that there is already an energy barrier for adsorption at low surface coverage. This energy barrier was found to limit the adsorption of phosvitin (measured directly using ellipsometry) to the airwater interface ${ }^{13}$ and has also been mentioned by others. ${ }^{40,41,46}$ This energy barrier is caused by the difference in the dielectric constant of the aqueous and the air phase. The change in dielectric constant leads to asymmetry of the diffuse double layer surrounding a charged protein near the interface. Effectively, this results in an electrostatic repulsion that increases as the protein approaches the interface, as if an apparent image charge approaches the same interface from the low-dielectric gas phase. This phenomenon is known as the "image charge effect". ${ }^{14}$ It has been a matter of debate whether such a theoretical description can still be used to describe protein adsorption. The problem is that proteins are often not spherical, and they have heterogeneous charge distribution, while theoretical models often assume that they can be represented as such. Corrections have been made to include nonspherical shapes, ${ }^{12,20,33}$ but the effects of nonhomogeneous charge distributions are more complex to include. However, Roth et al. performed calculations for the interaction energy of lysozyme with a mica surface. ${ }^{37}$ They concluded that that the calculated interaction energy is not significantly different when the protein is modeled as a sphere rather than modeled using its 3D structure.

To obtain data that can be used for a quantitative description of the effects of electrostatic charge, ovalbumin was chemically modified using succinic anhydride. This modification is based on the reaction of succinic anhydride with the lysine residues of the protein, changing positively charged amino groups into negatively charged carboxylic groups. This approach has already been used to produce "charge ladders" of modified proteins, ${ }^{11}$ where the effective charge of mildly modified proteins shows linear correlation with the degree of modification. ${ }^{8}$ In the presented work, five protein variants with increasing net charge were obtained. The kinetics of adsorption and the properties of the adsorbed protein layer were studied using an ellipsometer that was mounted on a Langmuir trough in combination with a Wilhelmy plate surface tensiometer. The obtained results are analyzed using a theoretical model to obtain a validated quantitative analysis of the influence of increased protein net charge on the adsorption behavior of the proteins.

\section{Materials and Methods}

Ovalbumin was isolated as described previously ${ }^{23}$ with the only adaptation being that ovalbumin was eluted from the ion exchange material at $0.15 \mathrm{M} \mathrm{NaCl}$. Succinic anhydride, $O$ phthaldialdehyde (OPA), and 2-ethyl-5-phenylisoxazolium-3'sulfonate (Woodward's reagent K) were from Sigma-Aldrich (St. Louis, Missouri, USA). All other chemicals used were of analytical grade.

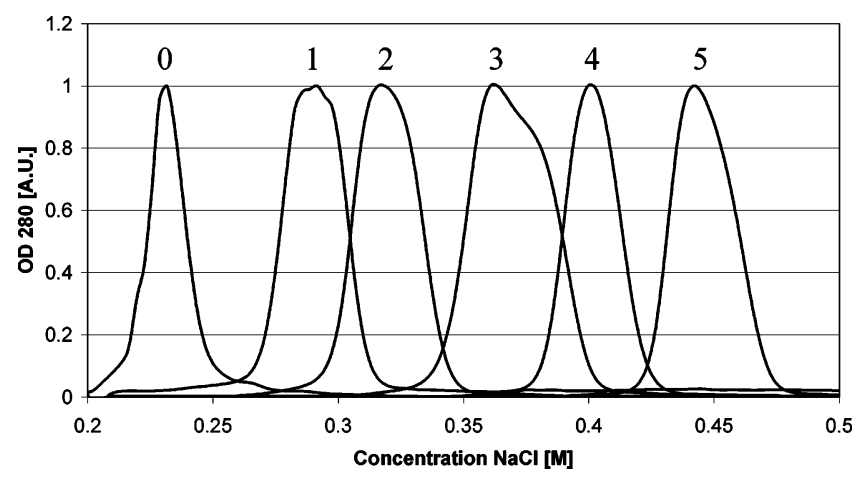

Figure 1. Ion exchange elution profiles for all ovalbumin variants (lines $0-5$ represent the results of $\mathrm{suc}_{0}-\mathrm{suc}_{5}$, respectively, $\mathrm{pH} 7.0$, anion exchange).

Succinylation of Ovalbumin. Via the reaction of succinic anhydride with lysine residues of proteins, additional carboxylate groups are introduced, resulting in more negative charges on the protein (at $\mathrm{pH} 7.0$ ). With the use of the method described by Kosters et al., ${ }^{23}$ three batches of succinylated ovalbumin were prepared with succinic anhydride:lysine ratios of $0.38,0.76$, and 1.9 (mole/mole). These ratios were chosen to modify $10 \%, 20 \%$, and $50 \%$ of the available lysine residues (or to introduce 2, 4, and 10 succinyl groups per protein, respectively).

Purification of Succinylated Ovalbumin. The procedure as described above results in heterogeneous modification of the protein. The three batches were fractionated using ion exchange chromatography to obtain more homogeneous fractions with increasing degrees of modification. The batches $(10 \mathrm{mg} / \mathrm{mL}$, $10 \mathrm{mM}$ phosphate buffer, $\mathrm{pH} 7.0+0.1 \mathrm{M} \mathrm{NaCl}$ ) were applied on an anion exchange column (Source-Q, $280 \mathrm{~mL}$ ) connected to an Äkta-explorer (Pharmacia Biotech, Sweden). The column was equilibrated in $10 \mathrm{mM}$ phosphate buffer, $\mathrm{pH}$ 7.0, containing $0.1 \mathrm{M} \mathrm{NaCl}$ (buffer A). The gradient was increased from $0 \%$ to $70 \%$ buffer $\mathrm{B}(10 \mathrm{mM}$ phosphate buffer, $\mathrm{pH} 7,0.5 \mathrm{M} \mathrm{NaCl})$ over 20 column volumes with a flow rate of $60 \mathrm{~mL} / \mathrm{min}$. From all three batches fractions were collected and pooled. These fractions were then dialyzed twice against distilled water and once against buffer $\mathrm{A}$ and were subsequently reapplied to the column using the same conditions. Final fractions were collected from 11 to $20 \%, 22-27 \%, 28-43 \%, 45-53 \%$, and $57-67 \%$ buffer B (further referred to as samples $\mathrm{suc}_{1}, \mathrm{suc}_{2}, \mathrm{suc}_{3}, \mathrm{suc}_{4}$, or $\operatorname{suc}_{5}$ ). The elution profiles of native or unmodified ovalbumin (further referred to as $\mathrm{suc}_{0}$ ) and $\mathrm{suc}_{1}-\mathrm{suc}_{5}$, on an analytical column under identical conditions, are shown in Figure 1. It can be seen that the peak width for all fractions is comparable to that of unmodified ovalbumin $\left(\mathrm{suc}_{0}\right)$, illustrating that all fractions are homogeneous in the degree of modification (DM). After collection the fractions were dialyzed extensively against distilled water, lyophilized, and stored at $-20{ }^{\circ} \mathrm{C}$.

Detection of Primary Amino Groups. The number of primary amino groups in ovalbumin variants was determined using $o$-phthaldialdehyde (OPA) as described by Church et al. ${ }^{10}$ The OPA reagent was freshly prepared by dissolving $40 \mathrm{mg}$ of OPA in $1 \mathrm{~mL}$ of methanol, followed by the addition of $25 \mathrm{~mL}$ of $0.1 \mathrm{M}$ sodium borate, $200 \mathrm{mg}$ of 2-(dimethylamino)ethanethiol hydrochloride (DMA), and $5 \mathrm{~mL}$ of $10 \%$ SDS. The total volume was adjusted to $50 \mathrm{~mL}$ with $\mathrm{H}_{2} \mathrm{O}$. Samples were prepared (in triplicate) by adding $65 \mu \mathrm{L}$ of a $0.1 \mathrm{mM}$ protein solution to $3 \mathrm{~mL}$ of the reagent solution. The concentration in the original protein solution was determined from the OD at $280 \mathrm{~nm}\left(\epsilon_{\mathrm{ova}}=29300 \mathrm{~cm}^{-1} \mathrm{M}^{-1}\right){ }^{3}$ After addition of the reagent solution the sample was left to equilibrate for $2 \mathrm{~min}$. The presence of alkyl-iso-indole derivatives formed after reaction 
of OPA with free amino groups was measured by the absorbance at $340 \mathrm{~nm}$. To calculate the number of primary amino groups per protein molecule a calibration curve was measured using leucine as a reference.

Detection of Carboxylic Groups. The number of carboxylic groups in ovalbumin variants was measured using the Woodward reagent $\mathrm{K}$ assay as described by Kosters et al. ${ }^{24}$ This method is based on the increase of the absorbance at $269 \mathrm{~nm}$ after reaction of the Woodward reagent $\mathrm{K}$ to the free carboxylic groups of the protein. All measurements were performed in duplicate.

Determination of $\xi$-Potential. The $\xi$-potential of the proteins was determined on a Zetasizer 2000 (Malvern Instruments Ltd., U.K.) with $10 \mathrm{mg} / \mathrm{mL}$ protein solutions (10 $\mathrm{mM}$ phosphate, $\mathrm{pH}$ 7.0, $\left.20{ }^{\circ} \mathrm{C}\right)$. Electrophoretic mobility was monitored at $150 \mathrm{~V}$ applied voltage using a $\mathrm{He}-\mathrm{Ne}$ laser at $632 \mathrm{~nm}$. The apparatus was calibrated according to supplier's instructions. Samples were analyzed in triplicate, and the measured $\zeta$-potential varied less than $10 \%$ between sample preparations.

Determination of Secondary Structure. Samples were dissolved $(0.1 \mathrm{mg} / \mathrm{mL})$ in a $10 \mathrm{mM}$ phosphate buffer at $\mathrm{pH} 7.0$. Far-UV CD spectra $(190-260 \mathrm{~nm})$ were recorded 16-fold and averaged on a Jasco J-715 spectropolarimeter (Jasco Corp., Japan) using a $1 \mathrm{~mm}$ quartz cuvette. Spectra were measured at both at 20 and $90{ }^{\circ} \mathrm{C}$, with a scan speed of $100 \mathrm{~nm} / \mathrm{min}$, a spectral resolution of $0.2 \mathrm{~nm}$, a bandwidth of $1.0 \mathrm{~nm}$, and a response time of $0.125 \mathrm{~s}$. All spectra were corrected for the corresponding protein-free sample and analyzed for the secondary structure estimates using a nonlinear least-squares fitting procedure with reference spectra as described by de Jongh et al. ${ }^{15}$

Evaluation of Tertiary Structure. The tertiary fold of ovalbumin variants was monitored with near-UV CD. Samples were dissolved $(1.0 \mathrm{mg} / \mathrm{mL})$ in a $10 \mathrm{mM}$ phosphate buffer $(\mathrm{pH}$ 7.0), and near-UV CD spectra $(250-350 \mathrm{~nm})$ were recorded 16-fold on a Jasco J-715 spectropolarimeter (Jasco Corp., Japan) and averaged, using a $1 \mathrm{~cm}$ quartz cuvette. Further settings of the machine were identical to those for the far-UV CD experiments. The recorded spectra were corrected by subtracting the spectrum of a protein-free sample.

The intrinsic fluorescence of the tryptophan and tyrosine residues of $0.1 \mathrm{mg} / \mathrm{mL}$ protein solutions in $10 \mathrm{mM}$ phosphate buffer ( $\mathrm{pH}$ 7.0) was measured on a Perkin-Elmer luminescence spectrometer LS $50 \mathrm{~B}$. The excitation and emission slits were set at $5 \mathrm{~nm}$. The excitation wavelength was 295 or $274 \mathrm{~nm}$, the excitation maxima of tryptophan and tyrosine, respectively. The emission spectra were recorded from 300 to $450 \mathrm{~nm}$ with a scan speed of $120 \mathrm{~nm} / \mathrm{min}$. Each spectrum was the average of two scans and was corrected for a protein-free sample.

Adsorption Kinetics. Adsorption to air-water interfaces of ovalbumin variants was monitored using a Multiskop ellipsometer (Optrell, Germany) combined with a Langmuir trough (Riegler and Kirstein, Germany) and Wilhelmy plate tensiometry. A good explanation of the theoretical background of ellipsometry has been given by Russev et al. ${ }^{38}$ With the use of the combination of ellipsometry and surface tensiometry, both the increase of surface load $(\Gamma)$ and surface pressure $(\Pi)$ in time could be measured. For all samples, the rate of adsorption from $0.25 \mathrm{mg} / \mathrm{mL}$ solutions (in $10 \mathrm{mM}$ phosphate, $\mathrm{pH} 7.0,20$ ${ }^{\circ} \mathrm{C}$ ) was measured at least in duplicate. All experiments were started by removing the interfacial layer with a custom-made suction device after which the clean interface was rapidly expanded to the maximum area (from 30 to $190 \mathrm{~cm}^{2}$; the first data points are typically taken $100 \mathrm{~s}$ after cleaning the interface).
TABLE 1: Chemical Characterization of the Degree of Modification for Succinylated Ovalbumin

\begin{tabular}{lcccccc}
\hline & $\begin{array}{c}\text { estimated } \\
\text { net charge } \\
(\mathrm{eV})\end{array}$ & $\begin{array}{c}\zeta \text {-potential } \\
(\mathrm{mV})\end{array}$ & $\begin{array}{c}{[\mathrm{NaCl}]} \\
\text { elution }\end{array}$ & $\begin{array}{c}\text { modified groups } \\
\left( \pm 1 \mathrm{NH}_{2} / \text { protein }\right)\end{array}$ & $\begin{array}{c}\text { theoret } \\
\mathrm{p} I\end{array}$ & $\begin{array}{c}\text { measd } \\
\mathrm{p} I\end{array}$ \\
\hline suc $_{0}$ & -12 & -17 & $0.21-0.25$ & 0 & 5.19 & 5.19 \\
suc $_{1}$ & -18 & -19 & $0.27-0.32$ & 3 & 4.86 & 5.09 \\
suc $_{2}$ & -20 & -20 & $0.29-0.35$ & 7 & 4.57 & 5.01 \\
suc $_{3}$ & -22 & -22 & $0.34-0.40$ & 10 & 4.39 & 4.96 \\
suc $_{4}$ & -24 & -24 & $0.37-0.43$ & 12 & 4.29 & 4.89 \\
suc $_{5}$ & -26 & -26 & $0.42-0.47$ & 14 & 4.19 & 4.83
\end{tabular}

In this way, the initial conditions for each experiment approximated $\Gamma=0 \mathrm{mg} / \mathrm{m}^{2}$ at $t=0 \mathrm{~s}$. The values for the ellipsometric angles $\Delta$ and $\psi$ were used to calculate the adsorbed amount, using software from the supplier (Optrell). To do this, the refractive index and thickness of the adsorbed protein layer are fitted in a model based on two bulk phases (air and water) and one adsorbed layer, with parameters: $n_{\text {air }}=1.000$, $n_{\text {proteinsolution }}=1.3327, \mathrm{~d} n / \mathrm{d} c=0.18 ;{ }^{27}$ the angle of incidence was $50^{\circ}$. Control experiments with distilled water between measurements confirmed that the cleaning method used (rinsing with ethanol and water) was sufficient to avoid contamination of the trough, i.e., the surface pressure of a clean surface remained $0 \mathrm{mN} / \mathrm{m}$ during compression.

Surface Rheology. Protein solutions $(0.1 \mathrm{mg} / \mathrm{mL}$ in a $10 \mathrm{mM}$ phosphate buffer at $\mathrm{pH}$ 7.0) were prepared $1 \mathrm{~h}$ before measurement. The surface tension was measured as a function of time $(0-5000 \mathrm{~s})$ on an automated drop tensiometer (ADT; I. T. Concept.), a technique described by Benjamins et al. ${ }^{5}$ Basically, an air bubble is formed at the tip of a syringe needle placed in a cuvette containing the protein solution. Both the cuvette and the syringe are temperature controlled $\left(20 \pm 0.1{ }^{\circ} \mathrm{C}\right)$. In these experiments, the bubble volume was kept constant at $4 \mathrm{~mL}$, using the computer-controlled syringe plunger to compensate for gas diffusion from the bubble. The surface elastic modulus was measured by inducing sinusoidal changes in the interfacial area with a period of $10 \mathrm{~s}$ and amplitude of $10 \%$. The modulus was calculated from the measured changes in surface tension and surface area averaged over a sequence of five sinuses; every $500 \mathrm{~s}$ such a sequence was performed. These measurements of the modulus did not affect the development of surface pressure in time. All samples were measured in duplicate on two separate occasions.

\section{Results and Discussion}

Preparation of Ovalbumin Variants. Succinylation of ovalbumin was performed at three different succinic anhydride to lysine ratios. Ion exchange chromatography was applied to obtain homogeneous fractions with increasing degrees of modification (DM), as described in the Experimental Section and shown in Figure 1. The DM of the fractions was determined using the OPA assay; the results are shown in Table 1. The results from the Woodward and the OPA assays show good correspondence (data not shown), and the DM was found to increase from 0 to $67 \pm 5 \%$ with regular intervals for the different variants, yielding theoretical net charges ranging from -12 to $-26( \pm 1)$. The isoelectric points of the variants were also determined experimentally and calculated. However, this approach could only be used qualitatively, since the isoelectric point of the protein is too close to the $\mathrm{p} K_{\mathrm{a}}$ of the carboxylic groups.

Characterization of Ovalbumin Variants. An extensive characterization of the chemical properties of the fractionated variants was performed to determine whether the chemical modification had induced any changes other than the increase 


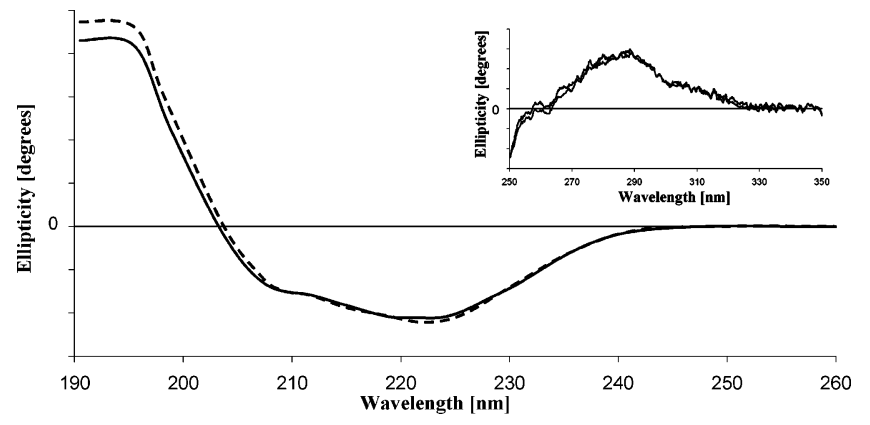

Figure 2. Far-UV CD spectra of $\operatorname{suc}_{0}$ (continuous) and $\operatorname{suc}_{5}$ (dashed line) ovalbumin; the inset shows the near-UV CD spectra of $\operatorname{suc}_{0}$ and $\operatorname{suc}_{5}\left(20^{\circ} \mathrm{C}, 10 \mathrm{mM}\right.$ phosphate buffer, $\left.\mathrm{pH} 7.0\right)$

in net charge. With the use of size exclusion chromatography, it was shown that all samples had identical elution patterns, confirming that all fractions consisted of monomeric protein (data not shown). As illustrated by the far-UV CD spectra for $\operatorname{suc}_{0}$ and $\operatorname{suc}_{5}$ (the most extremely modified sample) shown in Figure 2, no significant differences between the spectra were found. Secondary structure estimates derived from spectral analysis indicated a content of about $35 \% \alpha$-helix, $48 \%$ $\beta$-structure ( $\beta$-helix and $\beta$-turn), and $16 \%$ random coil for all variants; the differences in these values between samples was $<1 \%$. These values agree with other published results for far UV-CD of native ovalbumin. ${ }^{4}$ Intrinsic Trp/Tyr fluorescence was used to monitor any swelling or partial tertiary unfolding of the protein as a result of increased negative charge at the protein surface (data not shown). The data showed no change in intensity for any of the fluorophores, nor any difference in tyrosin-tryptophan energy transfer, indicating that the tertiary structure was also not affected by modification. This stability against modification agrees with findings by Bhaduri et al. ${ }^{6}$ but is in contrast with other literature where it has often been mentioned that chemical modification introduces large confor-

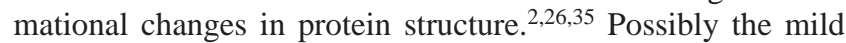
reaction conditions used during modification and the limited number of modified groups are the explanation for this discrepancy.

The structural stability of the variants was tested using differential scanning calorimetry. In all cases denaturation temperatures of $78 \pm 2{ }^{\circ} \mathrm{C}$ were found (results not shown). The exposed hydrophobicity was monitored by hydrophobic interaction chromatography. All variants eluted at the same concentration of ammonium sulfate $(0.7 \mathrm{M})$. Although no quantitative value can be obtained from this technique, it is sensitive to changes of the exposed hydrophobicity. The results clearly show that no differences result from the modification.

Since no discernible differences between the native and modified variants could be detected, any differences in adsorption behavior of the ovalbumin variants could be solely attributed to differences in net charge.

Adsorption Kinetics. After characterizing the modified proteins, their adsorption behavior was studied using ellipsometry. Both the adsorbed amount of protein (or surface load, $\Gamma$ ) and surface pressure $(\Pi)$ were measured as a function of time during adsorption from a bulk solution $(0.25 \mathrm{mg} / \mathrm{mL})$ to an initially protein-free air-water interface.

Adsorbed Amount. In Figure 3 typical curves of the adsorbed amount as a function of adsorption time are shown for $\mathrm{suc}_{0}-$ suc $_{5}$. Data were collected until $20000 \mathrm{~s}$, but since the surface layer was already almost saturated after $5000 \mathrm{~s}$ only these data are shown. It can be seen that increasing the net charge has two major effects. First, the rate of initial adsorption decreases

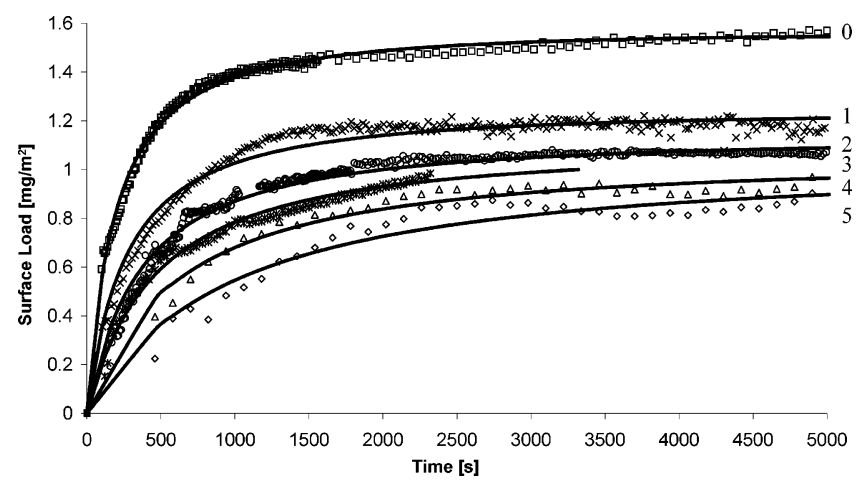

Figure 3. Increase of surface load in time for all ovalbumin variants $(0.25 \mathrm{mg} / \mathrm{mL}, 10 \mathrm{mM}$ phosphate buffer, $\mathrm{pH}$ 7.0) for long time. Markers are shown from typical results $\left(\square, \operatorname{suc}_{0} ; \times, \operatorname{suc}_{1} ; \bigcirc, \operatorname{suc}_{2} ; *, \operatorname{suc}_{3} ; \Delta\right.$, $\left.\operatorname{suc}_{4} ; \diamond, \operatorname{suc}_{5}\right)$. The lines are the results from fitting the data with eq 2 .

with increasing net charge, which indicates the presence of an energetic barrier for adsorption due to electrostatic repulsion. Second, the adsorbed amount at which saturation is reached ( $\left.\Gamma_{\text {sat }}\right)$ decreases from 1.6 to $0.8 \pm 0.1 \mathrm{mg} \mathrm{m}^{-2}$ (this is equal to 44 and $89 \mathrm{~nm}^{2} /$ molecule) for $\operatorname{suc}_{0}$ and $\operatorname{suc}_{5}$, respectively.

To obtain a more quantitative description of the results, the experimental data were fitted with equations based on the model of "random sequential adsorption" as presented by refs 39, 42, and 43. The RSA model assumes irreversible adsorption and calculates the chance of adsorption ( $P_{\text {adsorb}}$, given by eq 1$)$ as a function of surface coverage $(\theta)$ based on excluded volume effects.

$$
P_{\text {adsorb }}=1-4 \theta+\frac{6 \sqrt{3}}{\pi} \theta^{2}+1.4069 \theta^{3}
$$

where $\theta$ is the surface coverage [-], calculated from the surface load $\left(\Gamma,\left[\right.\right.$ molecules $\left.\left./ \mathrm{m}^{2}\right]\right)$ and the surface area taken up by adsorbed protein molecules $\left(\Omega,\left[\mathrm{nm}^{2} /\right.\right.$ molecule $\left.]\right)$ via $\theta=\Gamma \Omega$. The rate of adsorption is then calculated from eq 2

$$
\frac{\mathrm{d} \theta}{\mathrm{d} t}=k_{\mathrm{adsorb}} D_{\mathrm{b}} C_{\mathrm{b}} P_{\text {adsorb }}
$$

In this formula $k_{\text {adsorb }}$ is the rate constant of adsorption and $C_{\mathrm{b}}$ and $D_{\mathrm{b}}$ are the protein concentration and diffusion coefficient in the bulk phase, respectively. To fit the experimental data only $\Omega$ and $k_{\text {adsorb }}$ were used as fitting parameters. The proteins were assumed to behave as "hard" particles, i.e., $\Omega$ remains constant with time and surface pressure. This assumption is validated by two observations: (1) the unfolding of ovalbumin in the bulk is much slower than the adsorption process; (2) the equation of state of ovalbumin does not depend on the bulk concentration (results to be published). Further, it has been shown by infrared reflection spectrometry (IRRAS) measurements that the secondary structure of ovalbumin adsorbed at the air-water interface was independent of the bulk concentrations. ${ }^{25}$ From $k_{\text {adsorb }}$ an energy barrier for adsorption $\left(\Delta E_{\text {barrier }}\right)$ can be calculated via the Boltzmann equation.

$$
k_{\text {adsorb }}=e^{\frac{\Delta E_{\text {barrier }}}{k T}}
$$

The lines in Figure 3 are the result of the fitting procedure, and in Table 2 the values for the parameters $k_{\text {adsorb }}, \Delta E_{\text {barrier, }}$, and $\Omega$ are given. The energy barrier for adsorption increases linearly with increasing charge from $4.7 k T$ to $6.1 k T$ for suc $_{0}$ and $\operatorname{suc}_{5}$, respectively (or $0.14 k T$ per charge) as shown in Figure $4\left(R^{2}=0.95\right)$. The fitted effective radius $\left(R_{\mathrm{fit}}=\sqrt{\Omega / \pi}\right)$ of the 
TABLE 2: Calculated Values for the Effective Adsorption Rate and Energy Barrier for Adsorption

\begin{tabular}{|c|c|c|c|c|c|c|}
\hline & $\begin{array}{l}\text { estimated } \\
\text { net charge }\end{array}$ & $\begin{array}{c}k_{\text {adsorb }} \\
\left(\times 10^{-13}\right. \\
\left.\mathrm{m}^{3} \mathrm{~s}^{-1}\right)\end{array}$ & $\begin{array}{l}\Delta E_{\text {barrier }} \\
\quad(k T)\end{array}$ & $\begin{array}{c}R_{\mathrm{fit}} \\
(\mathrm{nm})\end{array}$ & $\underset{\left(\mathrm{mg} / \mathrm{m}^{2}\right)}{\Gamma_{\Pi>0}}$ & $\underset{\left(\mathrm{mg} / \mathrm{m}^{2}\right)}{\Gamma_{\mathrm{sat}}}$ \\
\hline $\operatorname{suc}_{0}$ & -12 & 6.4 & 4.7 & 2.5 & 1.1 & 1.6 \\
\hline $\operatorname{suc}_{1}$ & -18 & 4.5 & 5.1 & 2.8 & 1.0 & 1.3 \\
\hline $\operatorname{suc}_{2}$ & -20 & 3.4 & 5.3 & 2.9 & 1.0 & 1.1 \\
\hline $\mathrm{suc}_{3}$ & -22 & 2.7 & 5.6 & 3.0 & 0.9 & 1.0 \\
\hline $\operatorname{suc}_{4}$ & -24 & 2.6 & 5.6 & 3.1 & 0.8 & 0.9 \\
\hline $\operatorname{suc}_{5}$ & -26 & 1.6 & 6.1 & 3.2 & 0.7 & 0.8 \\
\hline $\begin{array}{l}\operatorname{suc}_{0} \\
\quad(300 \mathrm{mM} \mathrm{NaCl})\end{array}$ & -12 & 9.5 & 4.3 & 2.25 & 1.36 & 1.8 \\
\hline $\begin{array}{l}\mathrm{suc}_{2} \\
\quad 300 \mathrm{mM} \mathrm{NaCl})\end{array}$ & -20 & 9.6 & 4.3 & 2.35 & 1.34 & 1.8 \\
\hline
\end{tabular}

adsorbed proteins increases linearly with charge from 2.5 to $3.2 \mathrm{~nm}$ for $\operatorname{suc}_{0}$ to $\mathrm{suc}_{5}$, also shown in Figure $4\left(R^{2}=0.92\right.$; $0.07 \mathrm{~nm}$ per unit charge). This effective radius is the nearest center-to-center distance between adsorbing particles. For hardsphere particles this is equal to two times the radius of a particle. In the case of charged particles this nearest distance is determined by the balance between the kinetic energy of the adsorbing particle, the attraction between the adsorbing particle and the interface, and the repulsive energy between the particles. The repulsive energy between two particles (at separation $d=$ $2 R_{\mathrm{fit}}$ ) was calculated for all variants using eq 4 , representing the characteristic particle-particle repulsion energy. ${ }^{47}$

$$
U(d)=\frac{Z^{2} e_{c}^{2}}{\epsilon}\left[\frac{\mathrm{e}^{\kappa R_{0}}}{1+\kappa R_{0}}\right]^{2} \frac{\mathrm{e}^{-\kappa d}}{d}
$$

where $Z$ is the charge on the molecule, $e_{c}$ is the unit electron charge $\left(1.6 \times 10^{-19} \mathrm{C}\right), \epsilon$ is the dielectric permittivity of the medium ( $80 \mathrm{C}^{2} \mathrm{~N}^{-1} \mathrm{~m}^{-2}$ for water), $\kappa$ is the Debye screening length $\left[\mathrm{m}^{-1}\right], R_{0}$ is the radius of the protein $[\mathrm{m}]$, and $d$ is the distance between particles. From the calculations it was found that that the interaction energy at distance $2 R_{\mathrm{fit}}$ is similar for all variants (around $0.03 k T$ )

When the experiments were performed in the presence of 0.3 $\mathrm{M} \mathrm{NaCl}$, the fitted radius decreased to $2.3 \mathrm{~nm}$ (Table 2), which is close to the smallest radius of native ovalbumin. At this salt concentration the difference between the variants disappeared, as illustrated by the results for $\mathrm{suc}_{2}$. This further confirms that the increase in radius should be contributed to the high electrostatic repulsion between adsorbed proteins.

Equation of State. The relation between surface pressure and surface load is known as the "equation of state" and depends on the intermolecular interactions between adsorbed protein molecules. In Figure 5 typical results of the surface pressure are plotted against the time of adsorption. The surface pressure of $\mathrm{suc}_{0}$ increases after $500 \mathrm{~s}$. After this lag time the surface pressure increases sharply until a semiequilibrium value is reached. For $\operatorname{suc}_{0}$ a surface pressure of approximately $20 \mathrm{mN} / \mathrm{m}$ is reached after $6000 \mathrm{~s}$. With increasing net charge the time needed to reach equilibrium surface pressure increases to 7000 $\mathrm{s}$ for $\mathrm{suc}_{5}$, while the surface pressure that is reached is decreased $\left(8 \mathrm{mN} / \mathrm{m}\right.$ for $\mathrm{suc}_{5}$ after $\left.12000 \mathrm{~s}\right)$. In the initial stages of adsorption the average distance between adsorbed proteins is so large that there are no effective interactions. This can be illustrated by comparing Figure 3 and Figure 5, where it can be seen that for all variants the surface pressure starts to increase after $500 \mathrm{~s}$, while at the same time the adsorbed amount is lower for the variants with high net charge. The $\Pi-\Gamma$ curves compiled from tensiometry and ellipsometry data are shown in Figure 6.

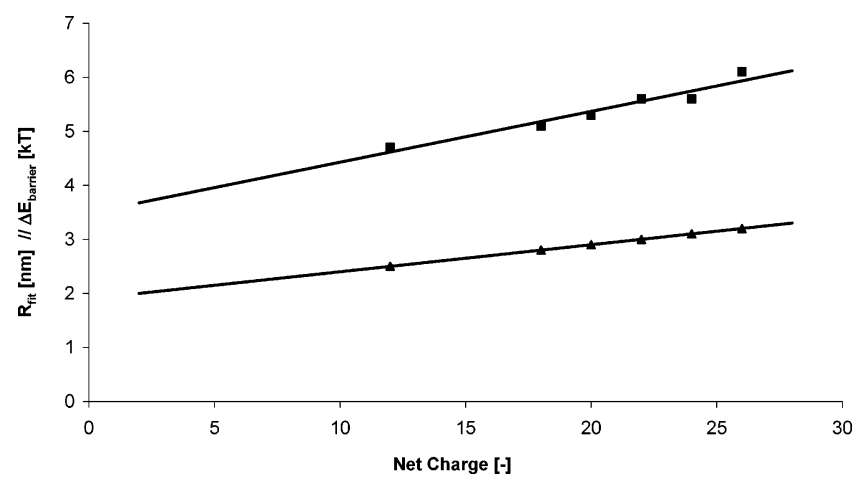

Figure 4. Fitted values for the radius $(\mathbf{\Lambda})$ and electrostatic barrier as a function of the protein net charge.

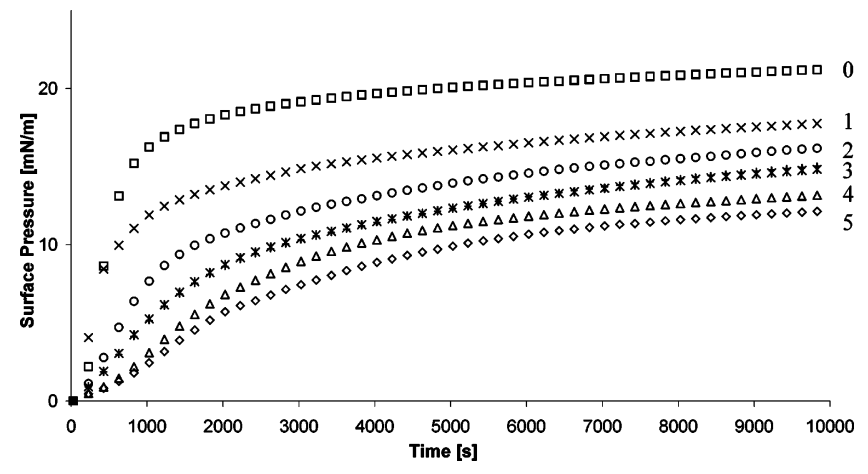

Figure 5. Increase of surface pressure in time for $\operatorname{suc}_{0}-\operatorname{suc}_{5}(0.25$ $\mathrm{mg} / \mathrm{mL}, \mathrm{pH} 7.0$ ). The markers are the same as those in Figure 3.

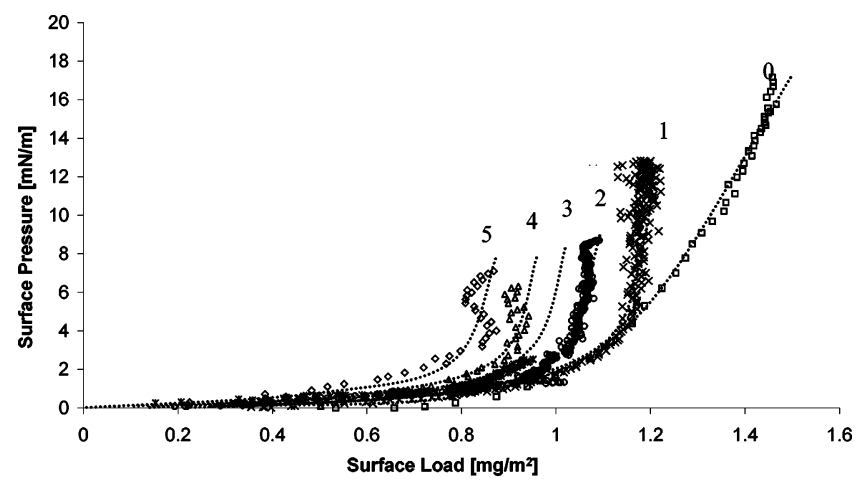

Figure 6. Surface pressure as a function of surface load (combination of the results shown in Figures 3 and 4); dotted lines are shown to guide the eye.

At longer time scales the ellipsometric data show more scattering, and those data are not used for calculations. Further, repeat experiments have shown that the trends indicated by the dotted lines are valid. The adsorbed amount where the surface pressure starts to increase $\left(\Gamma_{\Pi}>0\right)$ is around $1.1 \mathrm{mg} / \mathrm{m}^{2}$ for $\operatorname{suc}_{0}$ and decreases with increasing net charge to $0.7 \mathrm{mg} / \mathrm{m}^{2}$ for suc $_{5}$ (Table 2). With the use of the calculation for the characteristic particle-particle interaction given by Yuan et al., ${ }^{47}$ it was found that for all samples the interaction energy was similar (around $0.3 k T$ ) at the point where the surface pressure starts to increase.

Effect of Ionic Strength. If the observed difference in adsorption behavior between $\operatorname{suc}_{0}$ and modified protein is primarily the result of electrostatic interactions, an increase in ionic strength of the bulk solution should negate the differences. Under standard conditions (10 mM phosphate buffer, $\mathrm{pH} 7.0$ ) the reciprocal Debye length can be estimated to be $3.2 \mathrm{~nm}$; at high ionic strength (buffer $+300 \mathrm{mM} \mathrm{NaCl}$ ) the reciprocal Debye length is decreased to $0.6 \mathrm{~nm}$. 


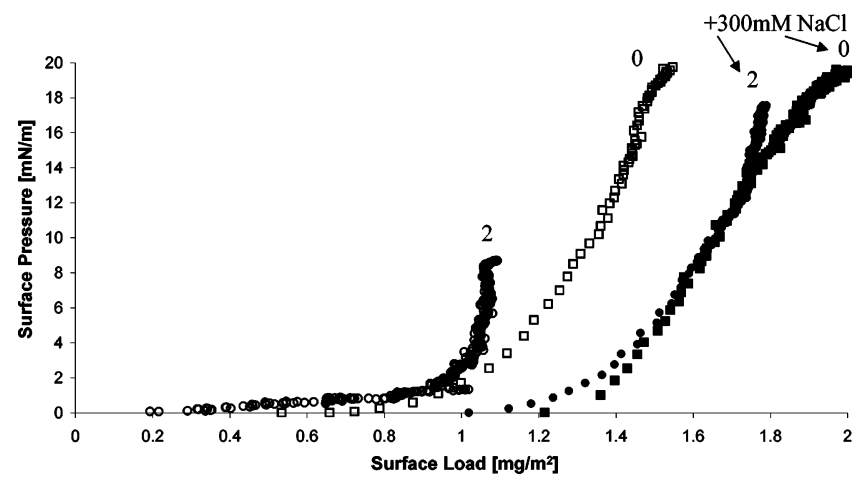

Figure 7. Equation of state for $\mathrm{suc}_{0}$ and $\mathrm{suc}_{2}$ at low (10 $\mathrm{mM}$ phosphate buffer) and high (300 $\mathrm{mM} \mathrm{NaCl})$ ionic strength.

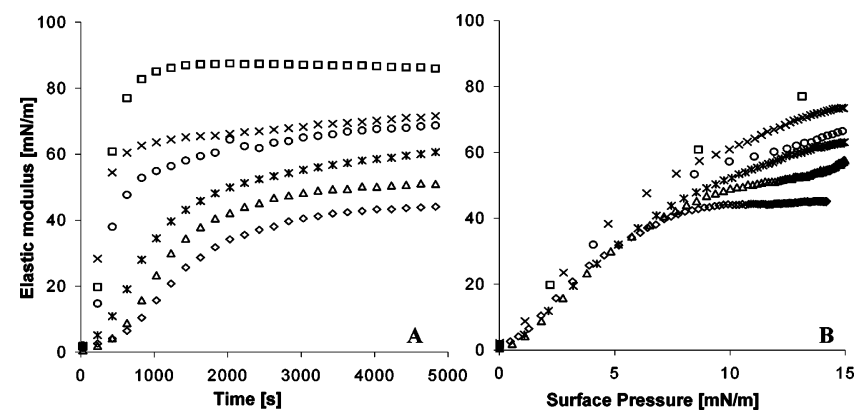

Figure 8. Elastic modulus vs time (A) or surface pressure (B) for all variants (top to bottom $\mathrm{suc}_{0}-\mathrm{suc}_{5}$ ) The markers are the same as those in Figure 3.

In Figure 7 the surface pressure of $\operatorname{suc}_{0}$ and $\mathrm{suc}_{2}$ is plotted versus the surface load at low and high ionic strength. At high ionic strength, $\Gamma_{\Pi}>0$ is increased for $\operatorname{suc}_{0}$ and the difference between $\Gamma_{\Pi}>0$ for $\operatorname{suc}_{0}$ and $\operatorname{suc}_{2}$ has completely disappeared. Moreover, the maximal surface load and surface pressure that is reached (after $5000 \mathrm{~s}$ ) is comparable for both proteins. That the high ionic strength leads to identical adsorption kinetics (data not shown) and equations of state further confirms that the modification only affected the electrostatic properties of the protein.

Surface Rheology. From the above the picture it emerges that the static surface pressure can be fully described in terms of a packed surface layer. The question arises whether this description is also valid for the dilatational properties of the surface. The dilatational elastic modulus of all variants was measured during adsorption, and the results are shown in Figure 8A. For $\mathrm{suc}_{0}$ the modulus increases to $90 \mathrm{mN} / \mathrm{m}$ in $1000 \mathrm{~s}$, and then it remains constant. With increasing net charge the time needed to reach equilibrium is increased and the equilibrium modulus is decreased $\left(40 \mathrm{mN} / \mathrm{m}\right.$ for suc $\left._{5}\right)$. This is similar to the development of surface pressure. A correction for the rate of adsorption can be achieved by plotting the modulus against the surface pressure (Figure 8B). Until a surface pressure of around $7 \mathrm{mN} / \mathrm{m}$, all samples follow the same line. At higher surface pressures the results diverge. The modulus of $\operatorname{suc}_{0}$ continues to increase almost linearly, while that of $\operatorname{suc}_{5}$ levels off. Some authors have proposed that a lower dilatational modulus is the result of desorption of molecules from the interface. From this perspective it is interesting to note that for the variants no desorption of proteins from the interface was observed in ellipsometric experiments (results not shown) so that the elastic modulus should be attributed to interactions between adsorbed molecules. This means that the different shape of the curves in Figure $8 \mathrm{~B}$ reflect the shift in the $\Pi-\Gamma$ relationship found in Figure 6.

\section{Conclusion}

With the use of five well-defined variants of ovalbumin with increased net charge, the influences of charge on adsorption kinetics and surface pressure development could be studied under constant system conditions. From adsorption experiments it became clear that the electrostatic charge affects the initial adsorption to the interface. This effect is due to the imagecharge potential, which is the result of the difference in dielectric permittivity of the aqueous and air phase. The contribution of net charge to the kinetic barrier to adsorption should be seen in relation to the gain in energy due to hydrophobic interaction with the interface, as described in previous work. ${ }^{45}$ As the adsorption continues the chance of the adsorbing particle to arrive close to an already adsorbed particle increases, leading to a second barrier to adsorption. This steric barrier is due to excluded volume effects and is described by the random sequential adsorption model. ${ }^{39}$ This model was used to describe the adsorption of all variants and resulted in good fits of the experimental data. The apparent size of the proteins as fitted by the model $\left(R_{\mathrm{fit}}\right)$ could be related to the charge of the protein variants. Calculations show that the interaction energy due to electrostatic repulsion at separation distance $d=2 R_{\mathrm{fit}}$ is constant for all variants, which validates the assumption that the "soft" interaction potential due to electrostatic interactions can be approximated by a hard core potential with a suitably chosen effective diameter. ${ }^{39,42,43,47}$

The development of surface pressure with increasing surface load was also affected by protein net charge. At increasing net charge the adsorbed amount needed to reach a certain surface pressure is decreased; the decrease in $\Gamma$ seems to follow the increase in $R_{\mathrm{fit}}$. By plotting $\Pi$ against $\theta$ this is confirmed, since the results for all variants follow the same curve (not shown). The changes in the equation of state were also visible in the results from the surface rheological measurements.

From the obtained results is may be clear that electrostatic properties are the most important molecular characteristic of globular proteins in understanding the adsorption process. One of the interesting findings is that the surface layer is less densely packed when the proteins have a higher charge. Preliminary data from neutron reflection experiments performed at ISIS (Didcot, UK) confirmed this idea. The higher amount of water at the interfacial layer might be important in processes such as coalescence of bubbles or emulsion droplets.

\section{References and Notes}

(1) Andrade, J. D.; Hlady, V. Protein Adsorption and Materials Biocompatibility. In Surface and Interfacial Aspects of Biomedical Polymers, 2nd ed.; Andrade, J. D., Ed.; Plenum Press: New York, 1985; pp 1-63.

(2) Batra, P. P. Int. J. Biochem. 1991, 23, 1375-1384.

(3) Batra, P. P.; Roebuck, M. A.; Uetrecht, D. J. Protein Chem. 1990, 9, 37-44. 108.

(4) Batra, P. P.; Uetrecht, D. Biochim. Biophys. Acta 1990, 1040, 102-

(5) Benjamins, J.; Cagna, A.; Lucassen-Reynders, E. H. Colloids Surf., A: Physicochemical and Engineering Aspects 1996, 114, 245-254.

(6) Bhaduri, A.; Matsudomi, N.; Das, K. P. Biosci. Biotechnol. Biochem. 1996, 35, 1559-1564.

(7) Blank, M.; Lee, B. B.; Britten, J. S. J. Colloid Interface Sci. 1975, $50,215-222$

(8) Carbeck, J. D.; Colton, I. J.; Anderson, J. R.; Deutch, J. M.; Whitesides, G. M. J. Am. Chem. Soc. 1999, 121, 10671-10679.

(9) Cho, D.; Narsimhan, G.; Franses, E. I. J. Colloid Interface Sci. 1997, 191, 312-325.

(10) Church, F. C.; Swaisgood, H. E.; Porter, D. H.; Catignani, G. L. J. Dairy Sci. 1983, 66, 1219-1227.

(11) Colton, I. J.; Anderson, J. R.; Gao, J. M.; Chapman, R. G.; Isaacs, L.; Whitesides, G. M. J. Am. Chem. Soc. 1997, 119, 12701-12709.

(12) Cornec, M.; Cho, D.; Narsimhan, G. J. Colloid Interface Sci. 1999, $214,129-142$. 
(13) Damodaran, S.; Xu, S. Q. J. Colloid Interface Sci. 1996, 178, 426435 .

(14) Datwani, S. S.; Stebe, K. J. J. Colloid Interface Sci. 1999, 219, 282-297.

(15) de Jongh, H. H. J.; Goormaghtigh, E.; Killian, J. A. Biochemistry 1994, 33, 14521-14528.

(16) Duhkin, S. S.; Kretzschmar, G.; Miller, R. The Dynamics of Adsorption at Liquid Interfaces. In The Dynamics of Adsorption at Liquid Interfaces, 1st ed.; Elsevier: Amsterdam, The Netherlands, 1995; Vol. 1, pp 100-139.

(17) Hartley, G. S.; Roe, J. W. Trans. Faraday Soc. 1940, 36, 101109

(18) Hauser, E. A. J. Phys. Chem. 1941, 45, 644-659.

(19) Haynes, C. A.; Sliwinsky, E.; Norde, W. J. Colloid Interface Sci. 1994, 164, 394-409.

(20) Hunter, J. R.; Kilpatrick, P. K.; Carbonell, R. G. J. Colloid Interface Sci. 1991, 142, 429-447. 3713

(22) Koseki, T.; Kitabatake, N.; Doi, E. J. Biochem. 1988, 27, 425430

(23) Kosters, H. A.; Broersen, K.; de Groot, J.; Simons, J.; Wierenga, P.; de Jongh, H. H. J. Biotechnol. Bioeng. 2003, 84, 61-70.

(24) Kosters, H. A.; de Jongh, H. H. J. Anal. Chem. 2003, 75, 25122516.

(25) Kudryashova, E. V.; Meinders, M. B. J.; Visser, A.; van Hoek, A.

de Jongh, H. H. J. Eur. Biophys. J. Biophys. Lett. 2003, 32, 553-562.

(26) Lakkis, J.; Villota, R. J. Agric. Food Chem. 1992, 40, 553-560.

(27) Longsworth, E. G. J. Am. Chem. Soc. 1948, 70, 2719-2724.

(28) Lu, J. R.; Su, T. J.; Howlin, B. J. J. Phys. Chem. B 1999, 103, $5903-5909$
(29) Luey, J. K.; McGuire, J.; Sproull, R. D. J. Colloid Interface Sci. 1991, 143, 489-500.

(30) Macritchie, F. J. Colloid Interface Sci. 1985, 105, 119-123.

(31) Macritchie, F.; Alexander, A. E. J. Colloid Sci. 1963, 18, 458463.

(32) Macritchie, F.; Alexander, A. E. J. Colloid Sci. 1963, 18, 464469.

(33) Narsimhan, G.; Uraizee, F. Biotechnol. Prog. 1992, 8, 187-196.

(34) Norde, W. Adv. Colloid Interface Sci. 1986, 25, 267-340.

(35) Qasim, M. A.; Salahuddin, A. Biochim. Biophys. Acta 1978, 536, $50-63$.

(36) Ramsden, J. J. Adsorption Kinetics of Proteins. In Encyclopedia of Surface and Colloid Science; Hubbard, A. T., Ed.; Marcel Dekker: New York, 2002; pp 240-261.

(37) Roth, C. M.; Lenhoff, A. M. Langmuir 1993, 9, 962-972.

(38) Russev, S. C.; Arguirov, T. V.; Gurkov, T. D. Colloids Surf., B 2000, 19, 89-100.

(39) Schaaf, P.; Talbot, J. J. Chem. Phys. 1989, 91, 4401-4409.

(40) Sengupta, T.; Razumovsky, L.; Damodaran, S. Langmuir 1999, 15, 6991-7001.

(41) Song, K. B.; Damodaran, S. Langmuir 1991, 7, 2737-2742.

(42) Talbot, J.; Tarjus, G.; Van Tassel, P. R.; Viot, P. Colloids Surf., A 2000, 165, 287-324

(43) Van Tassel, P. R.; Viot, P.; Tarjus, G.; Ramsden, J. J.; Talbot, J. J. Chem. Phys. 2000, 112, 1483-1488.

(44) Ward, A. F. H.; Tordai, L. J. Chem. Phys. 1946, 14, 453-461.

(45) Wierenga, P. A.; Meinders, M. B. J.; Egmond, M. R.; Voragen, F.; de Jongh, H. H. J. Langmuir 2003, 19, 8964-8970.

(46) Xu, S. Q.; Damodaran, S. Langmuir 1992, 8, 2021-2027.

(47) Yuan, Y.; Oberholzer, M. R.; Lenhoff, A. M. Colloids Surf., A 2000, 165, 125-141. 